\title{
The positive and negative transcriptional regulation of the Drosophila Gapdh-2 gene
}

\author{
Xiao-Hong Sun, ${ }^{1}$ John T. Lis, and Ray $\mathrm{Wu}^{2}$ \\ Section of Biochemistry, Molecular and Cell Biology, Cornell University, Ithaca, New York 14853 USA
}

\begin{abstract}
One of the genes encoding glyceraldehyde 3-phosphate dehydrogenase of Drosophila melanogaster, Gapdh-2, is expressed in all cell types examined, but its level of expression is regulated developmentally. Here we report the analysis of the regulatory sequences for the transcription of Gapdh-2. We have generated Gapdh-2-LacZ fusion genes in which the 5'-flanking sequence of Gapdh-2 has been mutated. Examination of the expression of these fusion genes, which have been introduced by transfection into the Schneider II cell line and by germ-line transformation into flies, led to the identification of two distinct regulatory regions, URS-1 and URS-2, within the first 145 bp of the 5'-flanking sequence of Gapdh-2. URS-1 activates transcription throughout the development of Drosophila. However, URS-2 exhibits a dual function during the development. It clearly represses transcription in Schneider II cells, and perhaps also in mid-stage embryos. In contrast, it activates transcription in larvae and adult flies. Thus, URS-2 plays a key role in the developmental regulation of Gapdh2. Additionally, the efficient transcription of Gapdh-2 in larval and adult stages appears to depend on a synergistic function of URS-1 and URS-2.
\end{abstract}

[Key Words: Positive control; negative control; Gapdh-2; developmental regulation; germ-line transformation; cell culture transfection]

Received December 21, 1987; revised version accepted April 18, 1988.

Transcriptional regulation of a eukaryotic gene is mediated by the interactions of specific proteins with cisacting sequence elements. These interactions either positively or negatively regulate the frequency with which nearby genes are transcribed (Maniatis et al. 1987). Although the molecular mechanisms of this regulation still remain to be defined, there are examples of interplay of both positively and negatively acting elements on a single gene (Johnson and Herskowitz 1985; Goodbourn et al. 1986; Nir et al. 1986).

Here we describe the functional dissection of the regulatory region of Drosophila melanogaster gene Gapdh-2, which encodes a very abundant glycolytic enzyme, glyceraldehyde 3-phosphate dehydrogenase. This gene is expressed in all cell types examined; however, its level of transcription is regulated developmentally (X.-H. Sun et al., in prep.). The level of expression of Gapdh-2 is determined by two distinct regulatory sequences, URS-1 and URS-2. We describe how these sequences cooperate through their positive and negative activities to set the level of transcription during development of Drosophila.

\footnotetext{
'Work described here was taken in part from a dissertation submitted to Cornell University for the degree of Doctor of Philosophy. Present address: Department of Biology, Massachusetts Institute of Technology, Cambridge, Massachusetts 02139 USA.

${ }^{2}$ Corresponding author.
}

Results

\section{Localization of the transcript start site}

By primer extension and S1-nuclease mapping techniques, Tso et al. (1985) have demonstrated that the $5^{\prime}$ noncoding sequence of Gapdh-2 mRNA is approximately $48 \mathrm{bp}$ long and is interrupted by an intron located $30 \mathrm{bp}$ from the transcription start. Based on the positions of the sequences homologous to the $5^{\prime}$ and $3^{\prime}$ splicing signals and a putative TATA box, the authors proposed that the intron was 430 bases in length. Here we try to locate the transcription start site and $5^{\prime}$ splice site experimentally by sequencing a Gapdh-2 cDNA. We screened $2.4 \times 10^{5}$ phage plaques from a $\lambda$ gt10 library containing Drosophila adult cDNA with a probe containing about $200 \mathrm{bp}$ of the sequence $5^{\prime}$ to the protein coding sequence and $30 \mathrm{bp}$ of the coding sequence of Gapdh-2. The longer of the two clones obtained was sequenced, and the sequence is aligned in Figure 1 with the genomic sequence. The cDNA sequence confirms the previous assignment of the $3^{\prime}$ splicing site, which is $18 \mathrm{bp}$ upstream from the ATG codon. However, the data indicate that the intron is 74 bases in length instead of $430 \mathrm{bp}$ as proposed. Upstream of this intron is a 28 -bp sequence found in this cDNA clone. The size of this first exon is in good agreement with that estimated $(28-31$ bp) from the primer extension and S1-nuclease mapping 

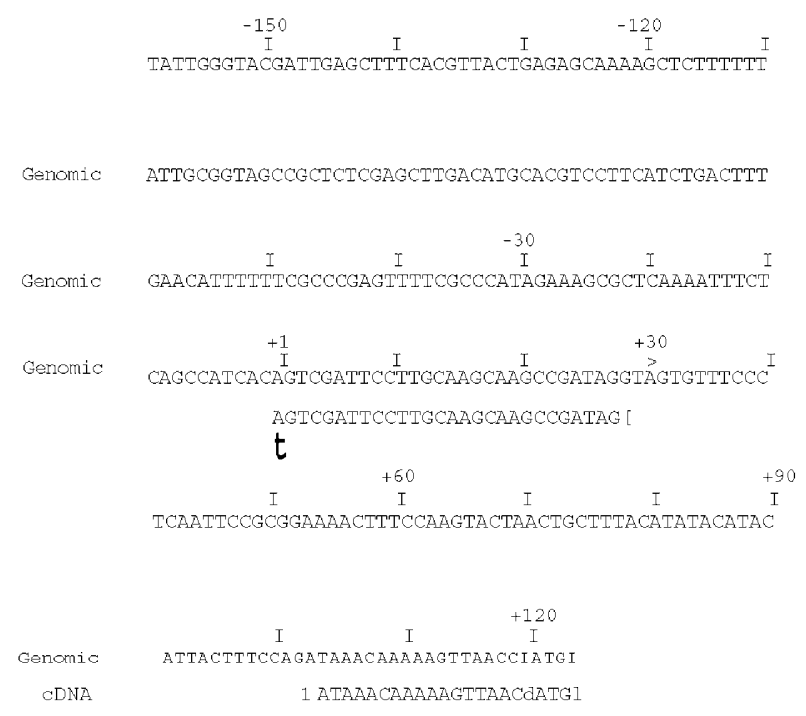

Figure 1. The 5' noncoding and flanking sequences of Gapdh-1 genomic DNA and CDNA. The genomic sequence (top line) of Gapdh-1 is compared with the cDNA sequence \{bottom line). The bracketed broken hne represents the 74-bp intron that has been spHced out in the cDNA clone. The 5' and 3' splicing signals are underlined. The arrow indicates the $5^{\prime}$ end of the cDNA, which is numbered as +1 . The $5^{\prime}$ ends of the primer-extended products (Tso et al. 1985) are shown by asterisks.

results (Tso et al. 1985). The genomic sequence ACAGTC located near the terminus of the cDNA resembles the consensus signal sequence for transcription initiation of Drosophila mRNA, ATCAG/TTC/T (Hultmark et al. 1986). In general, transcription initiates at the first $\mathrm{A}$ residue of the consensus sequence, but in the case of ypl gene it starts at the second A residue (Hultmark et al. 1986). Thus, it is possible that the two A residues in the sequence ACAGTC of Gapdh-l can both serve as the transcription start sites, resulting in two first exons of 28 and $30 \mathrm{bp}$ long, which could correspond to the primer-extended products observed by Tso et al. (1985). The clone sequenced here represents the shorter species.

\section{$145^{\prime}$ bp 5'-flanking sequence of Gapdh-2 is adequate for its high-level transcription}

A series of Gapdh-2-LacZ fusion gene constructs containing various 5 ' deletions in the flanking sequence of Gapdh-2 is illustrated in Figure 2. Each of the constructs was introduced into Drosophila Schneider II cells by transfection, and p-galactosidase activities were measured. Since the mutations were introduced only in the sequences upstream from the transcription unit of all constructs, the differences in p-galactosidase activities of the transfected cells were assumed to reflect the differences in the level of transcription of these constructs. The correlation between the level of transcription and the level of $\mathrm{p}$-galactosidase activity of $L a c Z$ fusion genes has been shown previously for $h s p 70-L a c Z$ fusion genes (Simon and Lis 1987). The p-galactosidase activities of the cells transfected with various constructs are compared with the activity of construct D937 transfected cells, which are assumed to represent the wild-type activity. The D937 construct contains a 937-bp sequence upstream of the transcription start, which has been shown elsewhere (X.-H. Sun, in prep.) to be sufficient for the expression of Gapdh-1 constructs at a level similar to that of the endogenous Gapdh-l gene. The relative activity in the cells transfected with each of the progressively 5 ' deleted Gapdh-l-LacZ fusion genes was similar to that of construct D937, until the deletion extended beyond position -145. Further deletions from this position resulted in as much as $85 \%$ reduction of p-galactosidase activity in the transfected cells. As a negative control, cells transfected with the vector plasmid carrying the entire $L a c Z$ gene showed no detectable p-galactosidase activity. Thus, the DNA sequence downstream from position - 145 contains sequence elements necessary for activating its transcription in Schneider II cells. Constructs D937, D145, D95, and D28 were also introduced into the germ line of Drosophila by P-element-mediated transformation technique. As examined by the $\mathrm{X}$-gal dissecting assay, the levels of expression at different developmental stages were examined by X-gal dissecting assay, and the results were consistent with those observed in the cell culture.

\section{URS-1 contains a positive regulatory element}

The presence of a positive regulating region, termed URS-1, located between nucleotides -95 and -145 of Gapdh-1, was demonstrated by two lines of evidence. First, as described above in Figure 2, deletions downstream from -145 reduced the transcription efficiency of the Gapdh-I-LacZ genes in cultured cells. This indicates that the 5 ' boundary of URS-1 is between -145 and -138 . Second, internal deletions in the region between - 28 and - 79 , or between - 28 and -95 shown in Figure 3, did not reduce expression in ID79/28 or ID95/28. In addition, a 49-bp insertion at -95 in con- 


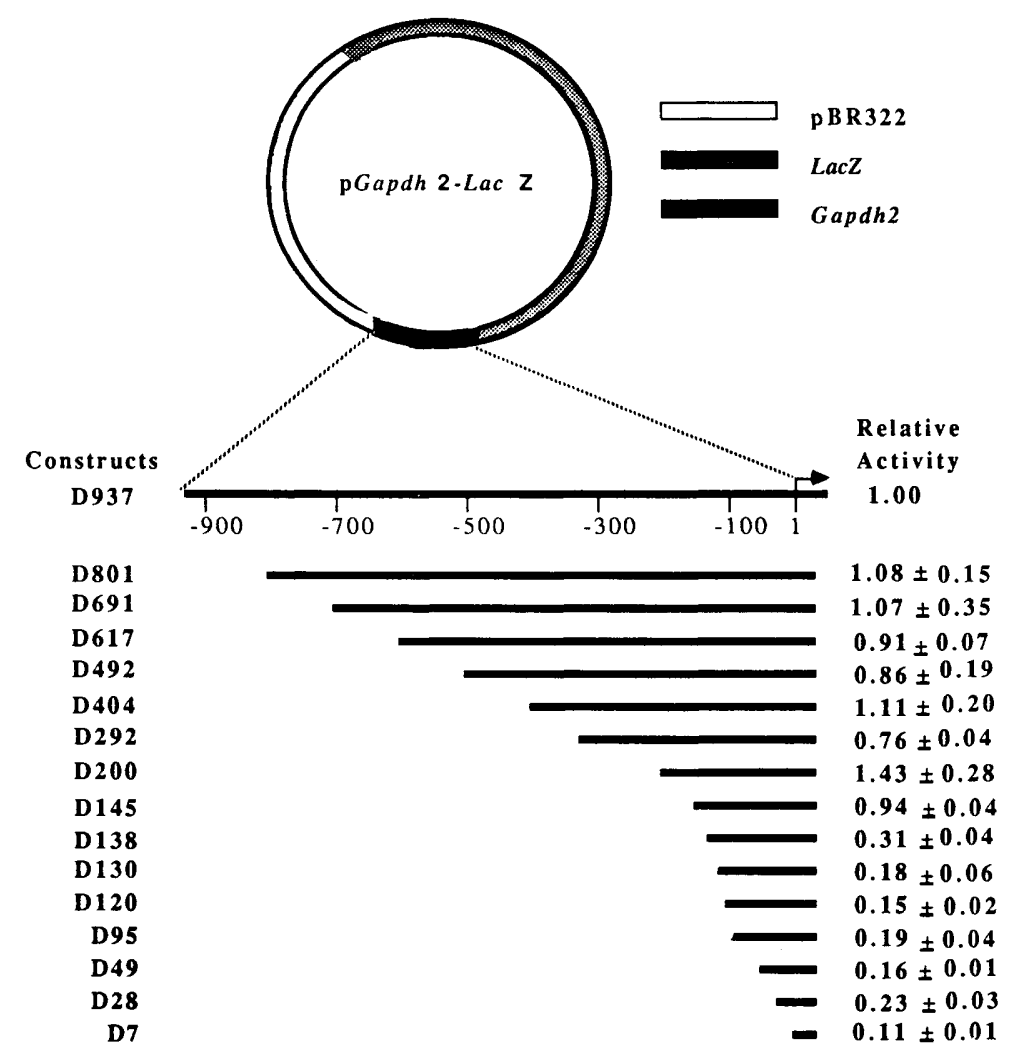

Figure 2. The $5^{\prime}$ deletion analysis of the upstream sequence of Gapdh-2. The 5' deletion constructs were generated from a parental plasmid of a Gapdh-2-LacZ fusion gene. This plasmid illustrated by a filled circle contains 6-kb LacZ sequence (dotted area) and 1090-bp Gapdh-2 sequence (dark area) in the pBR322 vector (open area). The 937-bp 5'-flanking sequence of Gapdh-2 in the parental plasmid is enlarged in the lower part of the figure. The thick lines represent the 5 '-flanking sequences included in the constructs. All the constructs have the same sequence as the parental plasmid except that they contain different 5 '-deleted flanking sequences of Gapdh-2, as indicated by their names. The numbers under the uppermost thick line indicate the position of the nucleotides relative to the transcription start site. The relative activities were obtained by comparing the normalized $\beta$-galactosidase activities of the transfected cells of each of the constructs with the activity of construct D937-transfected cells. The relative activities are presented as the average $\pm S E$. struct ID95-49 in Figure 3 also did not affect expression. Therefore, the 3 ' boundary of the URS-1 is located upstream of -95 .

The URS-1 region was characterized further to determine if it possessed enhancer-like properties. When this region was placed in an inverted orientation relative to the transcription start site, as shown by the arrow in construct ID95/28r in Figure 3, it functioned equally as well as in its natural orientation, such as in construct ID 95/28 in Figure 3. Moreover, no difference in its ability to stimulate expression was noticed when URS-1 was moved $49 \mathrm{bp}$ farther upstream of the transcription start site. When URS-1 was moved still farther upstream by inserting a fragment of about $800 \mathrm{bp}$ (originating from Gapdh-2 5'-flanking sequence from -146 to -937 ), URS-1 also activated expression, but with a greatly reduced efficiency. Thus, URS-1 functions efficiently as an activator in both orientations and over a limited distance relative to the transcription start site of the Gapdh-2 gene. URS-1 was also ligated to the Drosophila $A d h$ gene at various positions upstream of the TATA boxes of the larvae and adult-specific promoter regions. The ADH activities of the cells transfected with Adh gene constructs with or without URS-1 were essentially the same, indicating no detectable activation of the $A d h$ promoters by URS- 1 .

\section{URS-2 negatively regulates Gapdh-2 expression in Schneider II cells}

As noticed from the results shown in Figure 3, internal deletions between nucleotides -28 and -95 of Gapdh-2 did not decrease its expression in Schneider II cells, but rather, increased expression by about fivefold. Such an increase appeared not to be due to the closer proximity of URS-1 to the transcription start site, because replacing the sequence between nucleotides -28 and -95 with a pretested neutral sequence had the same effect as that of internal deletions (RP95/28 in Fig 4A). The neutral sequence was shown not to activate transcription by assaying a construct in which the sequence was inserted at -28 in construct D28 (Fig. 2). These results indicate the presence of a sequence that negatively regulates expression of Gapdh-2 in Schneider II cells. Since an internal deletion from -28 to -79 had the same effect as that of an internal deletion from -28 to -95 , the key sequences, called URS-2, must be located between nucleotides -28 and -79 .

When URS- 2 was deleted in construct D28 shown in Figure 2, the expression of the fusion gene was not increased relative to that of D95 where URS- 2 was intact. This indicates that URS- 2 exerts its negative role by interfering with the transcriptional activation by URS-1. However, this occurs only when it is located downstream of URS-1. Moving URS-2 to the front of URS-1 resulted in two constructs, RA1 and RA2 shown in Figure 4B, which failed to exert a negative effect. In construct RA1, the DNA fragment containing URS-1 and URS-2 $(-12$ to -145$)$ is inverted. In construct RA2, the DNA fragment containing only URS-2 $(-12$ to -95$)$ is moved to the front of URS- 1 . The expression in cells transfected with either of these two constructs is the 
Figure 3. Identification of URS-1. The 5'-flanking sequence of Gapdh-2 from nucleotides +1 to -145 is numbered and shown by a thick line. The box filled with crosses depicts URS-1. The thin lines, representing a linker sequence CGAGCTCGCCC, connect the deletion end points in the internal deletion (ID) constructs. The arrows indicate the orientations of URS-1. The outlined numbers show the original nucleotide positions before the inversion of the fragment. The broken lines represent the inserted foreign sequences of the sizes shown on the top. Relative activities were calculated as described in the legend of Figure 2.

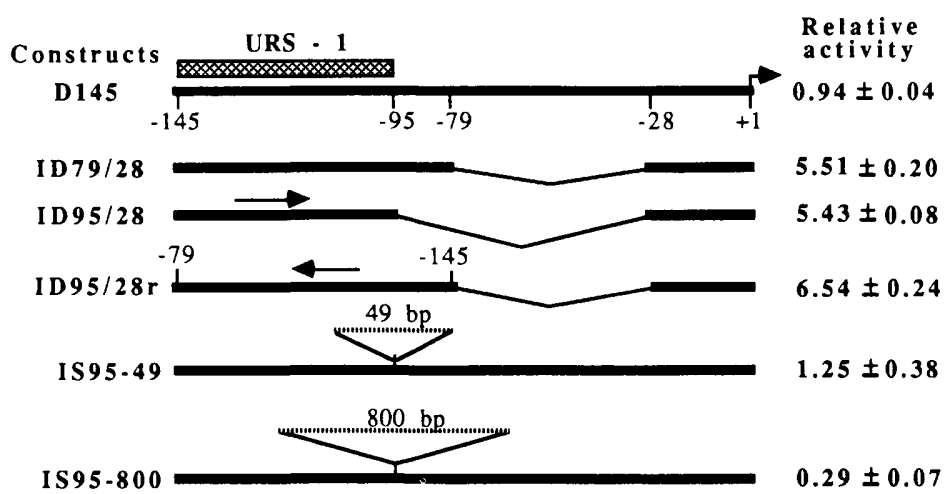

same as that of ID $95 / 28$, i.e., about fivefold higher than D937. These results indicate that the transcriptional activation effect of URS- 1 is not inhibited by URS- 2 when located upstream from URS-1.

Small deletions and multiple point mutations within URS-2 lead to partial inactivation of the activity of URS-2. For example, in constructs ID95/60 and ID79/49 (Fig. 4A), URS-2 was partially deleted from the distal end of the element relative to the transcription start and the expression of these fusion genes was about threefold higher than that of D937. Multiple point mutations by base-pair substitutions and deletions in the distal half of URS-2, as in construct MM6, also partially affected URS-2 activity (Fig. 4C).

Examination of the sequence of URS-2 revealed, in the proximal half of URS-2, a pair of 9-bp direct repeats which have the identical sequence TTTTCGCCC and are separated by $3 \mathrm{bp}$. Although single point mutations within the repeats in constructs MM1, MM2, or MM3 had no or minor effects, clusters of mutations in the repeats had rather obvious effects. For example, construct MM4, which contained 4 substitutions, 2-bp insertions, and 4-bp deletions in and around the proximal copy of the repeats, gave 2.9-fold higher expression than D937. Construct MM5 had five substitutions and a 4-bp deletion in and around the proximal repeat, as well as a substitution in the distal repeat. This construct was expressed at an even higher efficiency, 4.0-fold higher than D937. These results suggest that, although some mutations may be tolerated, both copies of the repeats are required for the negative effect of the proximal half of URS-2. This hypothesis is also supported by the analysis of construct ID95/42. Although ID95/42 contains the proximal repeat shown to be important for the negative effect in construct MM4, a deletion between -42 and -95 causes a fivefold increase in transcription efficiency, a result similar to construct $95 / 28$ where both repeats are deleted.

URS-2 acts like a positive element in larvae and adult flies, but not in embryos

Surprisingly, when construct ID79/28, containing a deletion of URS-2, was introduced into the flies by transformation, a much lower level of $\beta$-galactosidase activity was observed in larvae and adult flies of ID79/28 transformants as compared with the activity of D937 transformants (Fig. 5). The difference in $\beta$-galactosidase levels between D937 and ID79/28 transformed adult flies on average about 30 -fold (Table 1). This difference is especially apparent in the thoracic section of the adult flies. The thorax of D937 2-day adult female transformant was stained so intensely that it appeared black, whereas that of the ID79/28 transformant only appeared light blue in Figure 4. In fact, the dissected muscle fibers of ID79/28 transformants did not turn blue even after overnight incubation in a X-gal dissection buffer at room temperature, whereas that of D937 turned blue in 5 min under the same conditions. This result indicates that URS-2 can have a strong positive effect on the expression of Gapdh-2.

The expression of ID79/28 in adult flies was in contrast to that found in Schneider II cells where ID79/28 was transcribed fivefold more efficiently than D937 due to the loss of the negative effect of URS-2. Although the possibility exists that transfected genes behave abnormally because of the presence of multiple copies in a cell, it is conceivable that Gapdh-2 transcription is regulated differently in embryonically-derived Schneider II cells than in larvae or adult flies. This hypothesis is supported by the developmental profile of Gapdh-2 expression. Gapdh-2 is transcribed at a higher level in larval and adult stages, but at a lower level in Schneider II cells (X.-H. Sun et al., in prep.). Similar to the case in Schneider II cells, in the early and mid-stages of embryos and pupae, Gapdh-2 is also transcribed at lower levels.

To investigate whether the positive and negative effects of URS- 2 correlate with the different levels of endogenous Gapdh-2 expression at different developmental stages, we examined the expression of construct ID79/28, as measured by $\beta$-galactosidase activity, in early and mid-stage embryos, where Gapdh-2 is expressed at lower levels. One of the obstacles of this assay was that the GAPDH- $\beta$-galactosidase protein was very stable inside the cell, therefore maternal GAPDH- $\beta$-galactosidase protein in the embryos caused high background of $\beta$-galactosidase activity. To overcome this problem, a genetic cross was performed in which the ID79/28 transformant males were mated with virgin females of an Oregon $\mathrm{RP}_{2}$ strain la nearly wild-type strain 


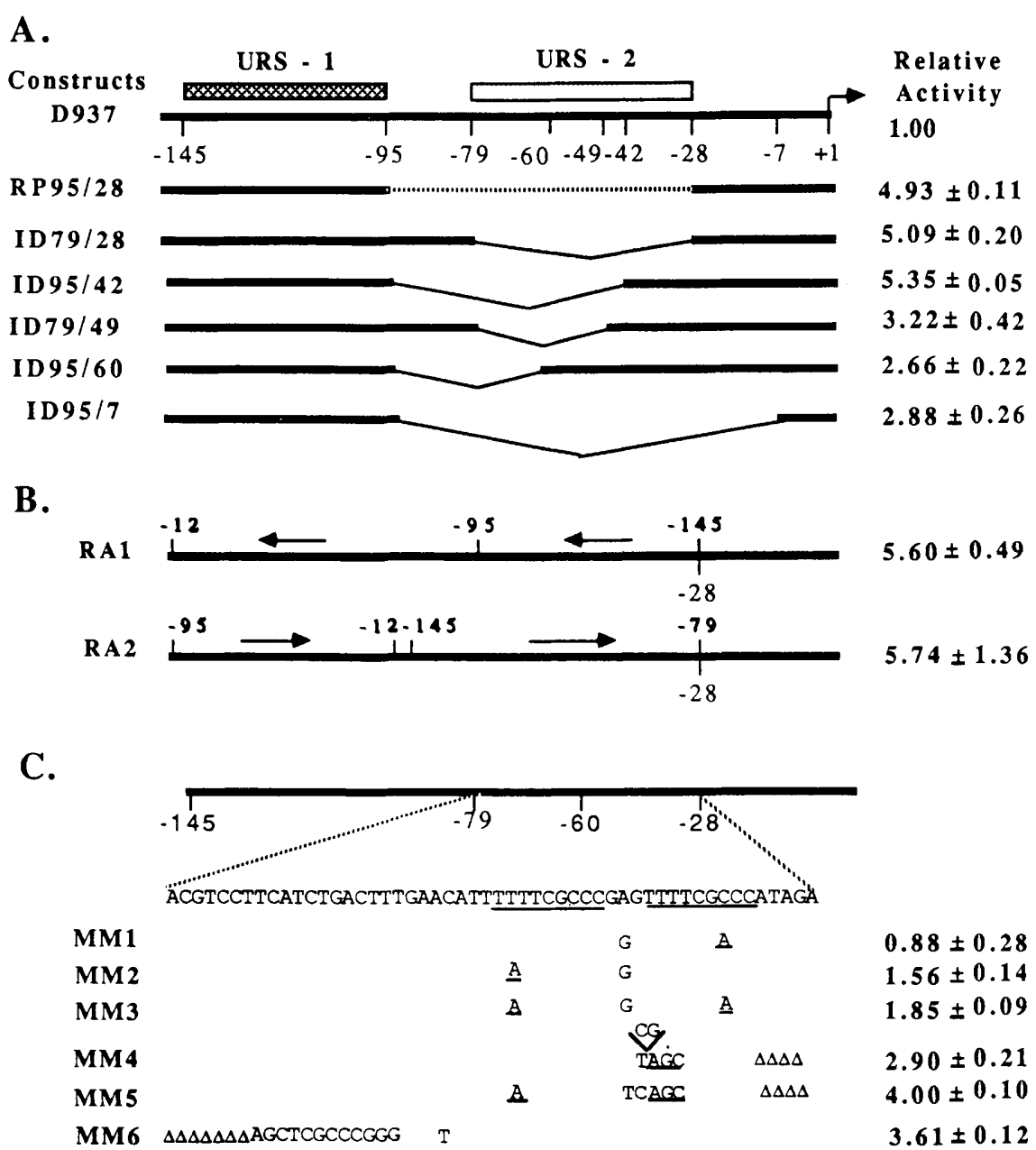

Figure 4. Identification of URS-2. The 5 -flanking sequence of Gapdh-2 from nucleotides +1 to -145 is numbered and shown by a thick line. URS-2 is illustrated by a box filled with dots. Relative activities were obtained as described in the legend of Figure 2 . $(A)$ Results obtained from the internal deletion (ID) constructs and a replacement (RP) construct where the broken line represents a foreign sequence. The thin lines connect the deletion end points with a linker whose sequence is CGAGCTCGCCC. $(B)$ Results of rearrangement mutation (RA) constructs. The orientations of the rearranged fragments are indicated by the arrows. The positions at which the rearrangements occur are marked with outlined numbers. (C) Relative activities of multiple mutation (MM) constructs. The sequence of URS- 2 is shown, and the direct repeats are underlined. Base substitution mutations in the constructs are shown at the corresponding positions. Deleted bases are represented by $\Delta$, and insertions are introduced to the corresponding position by nucleotides shown above the symbol $\mathrm{v}$.

except that the female flies do not hold eggs; strain provided by $\mathrm{R}$. MacIntyre). The offspring embryos were then collected and separated manually into early, mid, and late embryonic stages as judged by their morphology under a microscope. The D937 transformants were also mated and the resulting embryos were collected the same way. These embryos of ID79/28 and D937 were then assayed for $\beta$-galactosidase activity. Since the ID79/28 and D937 transformant males for the crosses were heterozygotes, only about $50 \%$ of the offspring embryos should contain the transformed gene and show the phenotype. Three independent transformants of D937 and ID79/28 were assayed, an example of which is shown in Figure 5. No $\beta$-galactosidase activity was detected in 4- to 6-hour embryos of either transformants. In 10- to 12-hour embryos, low activities were detected for both transformants. In addition, the ID79/28 em- bryos seemed to have a slightly higher activity than the D937 embryos, which was quantitated to be on the average of twofold in repeated assays of $\beta$-galactosidase activity of the 10- to 12-hour embryo extracts of each three independent transformants. Such a twofold difference may be too small to demonstrate convincingly that URS-2 functions negatively; however, at least it shows that URS-2 does not act positively on the expression of the Gapdh-2 at this stage. Conversely, D937 is expressed at a level of about fourfold higher than ID79/28 in the 14-to 16-hour embryos, a stage where the endogenous Gapdh-2 is expressed at a higher level. Taking into account the expression of ID79/28 in embryo, larvae, and adult, as well as in Schneider II cells, we propose that Gapdh-2 is regulated in two different ways mediated by URS-2 during development. URS-2 activates transcription in larvae and adult flies as well as in late-stage em- 
Sun et al.

D937

4-6 hr. embryos

10-12 hr. embryos

14-16 hr. embryos

3rd. instar larva

2 day adult female
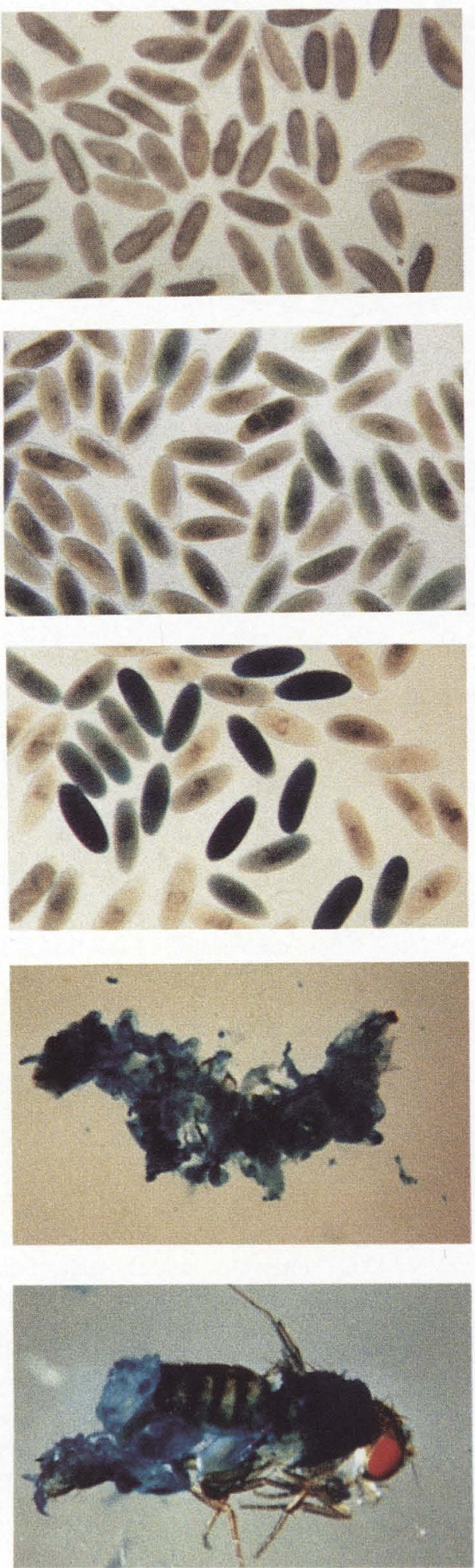

ID79/28
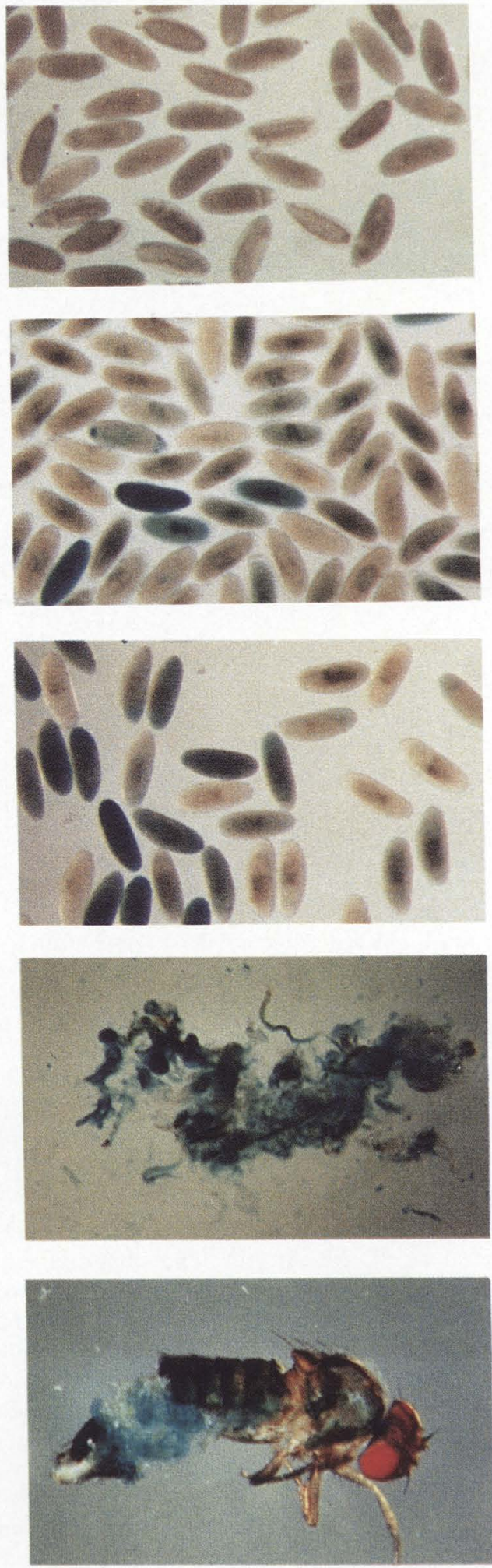

Figure 5. Expression of D937 and ID $79 / 28$ at different stages of development. The samples of the indicated developmental stages were incubated in an X-gal dissection buffer for $24 \mathrm{hr}$ for the embryos, $1 \mathrm{hr}$ for the larvae, and 30 min for adult flies. The embryos of various stages were selected under microscope according to their morphology. The samples were photographed with a Zeiss SR dissecting microscope at $32 \times$ magnification for embryos and $20 \times$ magnification for larvae and adult flies with a Kodak VRG color film. The levels of expression are indicated by the intensities of the blue color. 
bryos, but represses transcription in Schneider II cells and perhaps in mid-stage embryos.

\section{Localization of the DNA sequence responsible for the positive effect in URS-2}

Analysis of the expression of construct ID79/28, which contains a deletion of URS-2 located between nucleotides -28 and -79 , has led to the discovery of the positive effect of URS-2 in larvae and adult flies. Further localization of the sequence responsible for the positive effect was carried out by assaying the expression of construct ID95/42 (Fig. 4A) and MM4 (Fig. 4C) in the adult transformant flies. The results are shown in Table 1 . Construct ID $95 / 42$ was expressed at a level similar to ID79/28, i.e., about 20 -fold reduced relative to D937. In contrast, the level of expression of construct MM4 was like that of wild type, D937. These results suggest that sequences required for the positive effect are located between nucleotides -42 and -79 . Mutations between nucleotides -28 and -42 as in construct MM4 cause a partial lost of the negative but almost no loss of the positive effect, suggesting that the sequences for the two effects are not identical but may overlap.

\section{The functions of URS-1 and URS-2 are synergistic in the adult stage}

URS-1 and URS-2 both activate transcription in adult flies, and they seem to depend on each other to achieve a high level of activation. Listed in Table 1 are the results of assaying expression of various constructs in adult transformant flies. In the D937 transformant, which carries a fusion gene with both URS-1 and URS-2, a very high level of $\beta$-galactosidase activity was detected and this activity was considered as wild-type activity. On the other hand, D28, which had neither URS-1 nor URS-2, showed $0.5 \%$ of wild-type $\beta$-galactosidase activity. Deletion of either URS-1 or URS- 2 also caused a dramatic reduction in expression. Construct ID79/28 contained a deletion of URS-2 and was expressed at about $3 \%$ of the wild-type efficiency, whereas construct D95, in which URS-1 was deleted, was expressed at $1.1 \%$ of wild-type efficiency. If URS-1 and URS-2 stimulate expression of Gapdh-2 independently, the sum of the $\beta$-galactosidase activities of D95 (DURS-1) and ID $79 / 28$ (AURS-2) should constitute the wild-type activity. However, this was not found to be the case. Thus, URS-1 and URS-2 appear to activate Gapdh-2 expression synergistically.

\section{Gapdh-2 does not contain a TATA box}

In the region $20-30 \mathrm{bp}$ upstream from the transcription start site of Gapdh-2, no sequence homologous to the TATA consensus sequence was found. In fact, no such sequence was found in the 145-bp region involved in Gapdh-2 transcription. However, the sequence present between nucleotides -7 and -28 appears to participate in transcription of Gapdh-2, since construct ID95/7 was expressed twofold less efficiently than ID95/28, as shown in Figure 4A.

\section{Discussion}

Two closely linked and distinct regions of DNA sequences, URS- 1 and URS-2, have been identified which regulate expression of Gapdh-2, presumably at the level of transcription. URS-1, located between nucleotides -95 and -145 , functions positively to increase expression of the gene throughout the development of Drosophila. URS-2, located between nucleotides -28 and -79 , functions either positively (in late embryonic stage and in larvae and adults) or negatively (in Schneider II cells and perhaps in mid-stage embryos).

URS-1 may play a role in the constitutive transcription of Gapdh-2

URS-1, like many positive regulatory elements in eukaryotic genes such as the yeast upstream activating sequences (UAS) in the CYC1, Gallo, His3, and His4 genes (reviewed by Guarante 1984, and by Struhl 1987), and also the GC box (Kadonaga and Tjian 1986) and the CCAAT box (Benoist and Chambon 1980) present in many mammalian or viral genes, possesses some of the functional features of enhancer elements. URS-1 resembles enhancer elements because it is capable of activating transcription efficiently when placed in both orientations and at a limited variable distance relative to the transcription start sites. However, it also differs from the enhancer elements because it activates transcription poorly when located a long distance upstream of the transcription start sites, and it does not activate the transcription of a heterologous gene, the Drosophila Adh gene. In addition, trans-acting factors have been found to bind to each of the above-mentioned elements. Preliminary results of bandshift experiments using Drosophila Schneider II cell nuclear extract indicate that URS-1 may also have protein(s) bound to it. Since URS-1 always functions positively in every cell type and developmental stage examined, it is likely that the URS-1 primarily plays a role in maintaining the constitutive level of transcription of Gapdh-2.

\section{URS-2 may play a role in regulating Gapdh-2 transcription during development}

URS-2 has a dual effect on transcription during the development of Drosophila. URS-2 repressed transcription in Schneider II cells and perhaps in embryos of midstage. Since Schneider II cell line has an embryonic origin and a similar low level of Gapdh-2 expression as the mid-stage embryos, it is understandable why URS- 2 has the same behavior in these two cases. However, the negative effect of URS- 2 in the embryos was not as apparent as observed in Schneider II cells. This quantitative difference may be explained by the possibility that the cellular components involved in the regulation of Gapdh-2 expression are slightly different in Schneider II cells and 
Sun et al.

Table 1. Transcriptional activation of URS-1 and URS-2 in adult flies

\begin{tabular}{|c|c|c|c|c|c|}
\hline Constructs & Description & Transformants & $\begin{array}{l}\beta \text {-Galactosidase } \\
\text { activities }\end{array}$ & $\begin{array}{l}\text { Average } \\
\text { activities }\end{array}$ & $\begin{array}{l}\text { Ratio to } \\
\text { D937 }\end{array}$ \\
\hline D937 & wild type (Fig. 1) & $\begin{array}{ll}36-1 \quad(\mathrm{~F}) \\
36-1 \quad(\mathrm{M}) \\
36-14(\mathrm{~F}) \\
36-14(\mathrm{M}) \\
36-26(\mathrm{~F}) \\
36-26(\mathrm{M})\end{array}$ & $\begin{array}{r}81.5 \\
31.3 \\
127.2 \\
77.9 \\
122.1 \\
74.1\end{array}$ & 85.7 & 1.00 \\
\hline ID79/28 & no URS-2 (Fig. 3A) & $\begin{array}{ll}32-5 & (\mathrm{~F}) \\
32-5 & (\mathrm{M}) \\
32-7 & (\mathrm{~F}) \\
32-7 & (\mathrm{M}) \\
32-58 & (\mathrm{~F}) \\
32-58 & (\mathrm{M})\end{array}$ & $\begin{array}{l}2.9 \\
2.2 \\
5.3 \\
3.3 \\
1.3 \\
1.7\end{array}$ & 2.8 & 0.033 \\
\hline D95 & no URS-1 (Fig. 1) & $\begin{array}{ll}33-9 & (\mathrm{~F}) \\
33-9 & (\mathrm{M}) \\
33-18 & (\mathrm{~F}) \\
33-18 & (\mathrm{M}) \\
33-28 & (\mathrm{~F}) \\
33-28 & (\mathrm{M})\end{array}$ & $\begin{array}{l}0.8 \\
0.3 \\
1.0 \\
0.4 \\
1.8 \\
0.9\end{array}$ & 0.9 & 0.011 \\
\hline D28 & no URS-1 and URS-2 (Fig. 1) & $\begin{array}{l}29-16(\mathrm{~F}) \\
29-16(\mathrm{M}) \\
29-85(\mathrm{~F}) \\
29-85(\mathrm{M}) \\
29-86(\mathrm{~F}) \\
29-86(\mathrm{M})\end{array}$ & $\begin{array}{l}0.3 \\
0.4 \\
0.6 \\
0.5 \\
0.3 \\
0.2\end{array}$ & 0.4 & 0.005 \\
\hline MM4 & mutations in the proximal end of URS-2 (Fig. 3C) & $\begin{array}{l}37-7 \quad(\mathrm{~F}) \\
37-7 \quad(\mathrm{M}) \\
37-28(\mathrm{~F}) \\
37-28(\mathrm{M}) \\
37-60(\mathrm{~F}) \\
37-60(\mathrm{M})\end{array}$ & $\begin{array}{l}40.0 \\
35.0 \\
81.9 \\
69.8 \\
67.6 \\
42.7\end{array}$ & 56.2 & 0.66 \\
\hline ID95/42 & deletion of the distal part of URS-2 (Fig. 3A) & $\begin{array}{l}38-42(\mathrm{~F}) \\
38-42(\mathrm{M}) \\
38-58(\mathrm{~F}) \\
38-58(\mathrm{M}) \\
38-63(\mathrm{~F}) \\
38-63(\mathrm{M})\end{array}$ & $\begin{array}{l}6.6 \\
4.0 \\
3.7 \\
3.2 \\
4.7 \\
3.0\end{array}$ & 4.2 & 0.05 \\
\hline
\end{tabular}

Flies used in the assays were heterozygote transformants of $2-3$ days old.

The $\beta$-galactosidase activities were the average of the triplicate results of the C-gal assays.

The unit of the activity is expressed as $\mathrm{OD}_{574} / \mathrm{hr}$ per 5 flies at $37^{\circ} \mathrm{C}$.

in the embryos, so that URS-2 may have a stronger effect in Schneider II cells than in the mid-stage embryos, or that the negative effect is somehow exaggerated by the multiple copies of the Gapdh-2 fusion genes transfected into Schneider II cells. Alternatively, a critical, yet undiscovered, developmental stage may exist where URS-2 has a negative effect on transcription like that seen in Schneider II cells. At any rate, URS- 2 has no positive effect on the expression of Gapdh-2 in mid-stage embryos.

In larval and adult stages, URS- 2 participates in the transcriptional activation of Gapdh-2. Deletion of URS-2 reduced the expression by 20 - to 30 -fold in adult flies. As larvae and adult flies have a higher energy demand, activation of Gapdh-2 by URS-2 may be required to elevate the rate of glycolysis. In addition, the fact that the expression of Gapdh-2 in the muscle cells of adult flies is more highly dependent on the presence of URS-2 suggests that the regulation of Gapdh-2 expression in adult muscle cells may be qualitatively different from that in nonmuscle cells. Since URS-2 exhibits different effects on transcription during development, it is likely to play a key role in the regulation of Gapdh-2 expression.

\section{Mechanistic relationships of URS-1 and URS-2}

As a negative regulator, URS-2, in conjunction with URS-1, resembles the inducible enhancer of the human $\beta$-interferon gene (Goodbourn et al. 1986). Within the enhancer of the $\beta$-interferon gene, a negative regulatory sequence is closely linked downstream from a constitutive transcription element and prevents enhancer activity prior to induction. However, unlike the negative 
regulatory sequence of the human $\beta$-interferon gene, URS-2 does not inhibit the positive effect of URS-1 when moved upstream from this element.

As a positive element, URS- 2 acts in concert with URS-1 to activate the transcription of Gapdh-2. Although the precise sequences mediating the positive effects in URS- 1 and URS- 2 are not known, URS- 1 and URS-2 do not show any apparent and extended sequence homology. This suggests that the two elements may not be associated with the same trans-acting transcription factor(s). Multiple distinct elements are involved in the regulation of genes like the metallothionein gene (Karin et al. 1984), and the SV40 early (McKnight and Tjian 1986) gene. The effects of these multiple elements in a gene may be additive or synergistic. In the Drosophila Gapdh-2 gene, the two distinct regulatory sequences clearly activate transcription in a synergistic manner.

\section{Materials and methods}

All recombinant DNA techniques were carried out according to Maniatis et al. (1982), except those described below. Drosophila germ-line transformation was performed as described by Lis et al. (1983).

\section{DNA transfection in cell culture}

Transfection in Drosophila cultured cells (Di Nocera and Dawid 1983| mediated by calcium phosphate-DNA precipitates was performed as follows. Drosophila Schneider II cells were grown at $22^{\circ} \mathrm{C}$ in $3 \mathrm{ml}$ of Schneider medium /Schneider 1972) containing $10 \%$ heat-inactivated fetal bovine serum in Falcon flasks to a density of about $5 \times 10^{6}$ cells $/ \mathrm{ml}$. The calcium phosphate-DNA precipitate was prepared by adding 200 $\mu l$ calcium-DNA solution $\left(0.25 \mathrm{M} \mathrm{CaCl}_{2}, 10-20 \mu \mathrm{g}\right.$ DNA $)$ to a $200 \mu \mathrm{l} 2 \times \mathrm{HeBS}$ solution $16 \% \mathrm{NaCl}, 0.07 \% \mathrm{KCl}, 0.04 \%$ $\mathrm{Na}_{2} \mathrm{HPO}_{4}, 0.2 \%$ dextrose, $1 \%$ HEPES, $\mathrm{pH} 7.1$ ). The calciumDNA solution was mixed immediately with the $2 \times \mathrm{HeBS}$ solution by a constant air-bubbling device during the addition. The precipitation mixture was incubated at room temperature for $30 \mathrm{~min}$ and then added to the cell culture. Two days later, expression of the genes was assayed.

\section{Deletion of the 5' region of Gapdh-2 by exonuclease III and S1 nucleases}

A 1.1-kb EcoRI-BamHI fragment containing the 5' regulatory region and noncoding sequence of Gapdh-2 was subcloned into pUC13. Fifty micrograms of the plasmid DNA was digested by EcoRI at the 5' end of the fragment. The linearized DNA was digested with exonuclease III (New England Biolabs) in a total volume of $100 \mu \mathrm{l}$ in the condition given by Guo and Wu (1983). Aliquots were taken at 5-min intervals and pooled together in an Eppendorf tube containing phenol and EDTA, which stop the reaction. The DNA was recovered by ethanol precipitation, and subjected to $\mathrm{S} 1$ nuclease digestion at $30^{\circ} \mathrm{C}$ in $300 \mu \mathrm{l}$ of $\mathrm{S} 1$ nuclease buffer ( $250 \mathrm{~mm} \mathrm{NaCl}, 30 \mathrm{~mm} \mathrm{NaOAc}, \mathrm{pH} 4.8,4.5 \mathrm{~mm}$ $\mathrm{ZnSO}_{4}$, and 100 units/ml S1 nuclease) for $30 \mathrm{~min}$, followed by phenol extraction and ethanol precipitation. Finally, the termini of the exonuclease III and S1-digested DNA were repaired by T4 polymerase to produce blunt ends for ligation. The deleted DNA was then digested with BamHI to excise the fragments, and electrophoresed on a $1 \%$ low-melting-point agarose gel. A smear of DNA of $1.1-\mathrm{kb}$ or smaller was observed and gel slices containing DNA of the desired sizes were excised. The fragments were then cloned into the SmaI and BamHI sites of M13 mpll. The deletion end points were determined by the dideoxynucleotide chain-termination sequencing method.

Deletion was also carried out from the BamHI site of the fragment $3^{\prime}$ to the transcription start by exonuclease III and $\mathrm{Sl}$ nucleases digestions. The shortened DNA termini were repaired by $\mathrm{T}_{4}$ polymerase and ligated to a Sst linker. The DNA was then digested with EcoRI fractionated on $1 \%$ low-meltingpoint agarose gel, and the desired fragments were cloned into EcoRI- and SstI-digested M13 mp10. Sequence analysis was carried out to define the exact deletion end points.

\section{Construction of plasmids}

A Gapdh-2-LacZ fusion gene plasmid was generated by inserting a Gapdh-2 DNA fragment into the EcoRI and SmaI sites of a vector, pMC1403 (Casadaban et al. 1980), containing the $E$. coli LacZ gene. This DNA fragment, which has an EcoRI site at the $5^{\prime}$ end and a blunt $3^{\prime}$ end generated by $\mathrm{S} 1$ nuclease overdigestion from a ClaI site in the coding region, contains $937 \mathrm{bp}$ of 5 '-flanking sequence, the 5 ' noncoding sequence, and the first $30 \mathrm{bp}$ of the coding sequences. Since a BamHI site was located immediately downstream from the SmaI site in the vector, the EcoRI and BamHI sites were used to excise the Gapdh-2 sequence for mutagenesis and insert back to assay the expression in this fusion plasmid. Various mutations in this EcoRIBamHI fragment were generated by recombinations of the $5^{\prime}$ and $3^{\prime}$ deleted M13 clones described above, as well as a few clones with point mutations created by site-directed mutagenesis. Details of the constructions of the plasmids were described elsewhere (Sun 1987).

\section{Assays for $\beta$-galactosidase activity}

ONPG assay of cell extract The procedure used for assaying $\beta$-galactosidase activity in cultured cells was based on that described by Amin et al. (1985). Cells (3 ml) transfected with various Gapdh-2-LacZ fusions genes were detached from the flask by repeatedly pipetting the medium up and down and spinning at $3000 \mathrm{~g}$ for $5 \mathrm{~min}$. The cell pellet was then washed once with PBS (10 mM Na phosphate, pH 7.0, $150 \mathrm{~mm} \mathrm{NaCl}$ ), and resuspended in $0.75 \mathrm{ml}$ of PBS. The cell suspension was sonicated and spun in an Eppendorf centrifuge for $5 \mathrm{~min}$. The supernatant was then used as cell extract.

In the ONPG (o-nitrophenyl- $\beta$-D-galactopyranoside) assay reaction, $0.1 \mathrm{ml} 4 \mathrm{mM}$ ONPG solution was incubated at $37^{\circ} \mathrm{C}$ for $15 \mathrm{~min}$ with $0.2 \mathrm{ml} \mathrm{Z}$ buffer $160 \mathrm{mM} \mathrm{Na} \mathrm{HPO}_{4}, 40 \mathrm{mM}$ $\mathrm{NaH}_{2} \mathrm{PO}_{4}, 10 \mathrm{mM} \mathrm{KCl}, 1 \mathrm{~mm} \mathrm{MgSO}, 50 \mathrm{~mm} \beta$-mercaptoethanol, $\mathrm{pH} 7.0)$ containing the amount of cell extracts $(10-100 \mu \mathrm{l})$ which catalyzes the reaction within the range for accurate $\mathrm{ki}$ netic assay. The reaction was stopped by adding $0.2 \mathrm{ml}$ of $1 \mathrm{M}$ $\mathrm{Na}_{2} \mathrm{CO}_{3}$. The readings at $\mathrm{OD}_{420}$ were used as an indication of the $\beta$-galactosidase activity. The $\beta$-galactosidase activity was expressed as $\mathrm{OD}_{420} / \mathrm{ml}$ cell extract. The control for the transfection condition and the concentration of the cell extracts was achieved by co-transfecting each of the Gapdh-2-LacZ fusion gene constructs with a Drosophila copia-CAT gene construct into the Schneider II cell. Thus, the $\beta$-galactosidase activity was normalized against the chloramphenicol acetyltransferase (CAT) activity of the same cell extract, and expressed as $\mathrm{OD}_{420}$ ' ml per unit of CAT activity.

$X$-gal tissue staining Staining of larvae and adult flies was performed essentially as described by Glaser et al. (1986), except that the glutaraldehyde treatment was omitted. 
To stain embryos, Drosophila embryos were collected by placing the adult flies of desired strains in half-pint milk bottles, the bottom of which had been replaced with bridal veil; the bottles were set on the grape agar plates at $25^{\circ} \mathrm{C}$, and were transferred to fresh grape agar plates at 2- to 4-hr intervals. The grape agar plates containing embryos were incubated further at $25^{\circ} \mathrm{C}$ for various lengths of time to obtain embryos of the desired stages. For critical staging of the embryos, dechorionated embryos were examined under an inverted light microscope according to the morphological criteria provided by Wieschaus and Nüsslein-Volhard (1986) and picked up with a capillary tube by suction.

Embryos on grape agar plates were brushed off and transferred to Eppendorf tubes containing embryo saline (ES) $\{0.7 \% \mathrm{NaCl}$, $0.4 \%$ Triton) washed with ES twice. For dechorionation, the embryos were treated with $0.5 \mathrm{ml} 100 \%$ Chlorox bleach for 1 min with vigorous shaking on an Eppendorf shaker, and $0.5 \mathrm{ml}$ of ES was then added to the tubes. When the embryos settled down to the bottom of the tubes, the liquid was removed with a fine-point Pasteur pipet and discarded. The embryos were then washed with ES twice, and permealized in hexane with vigorous shaking for $5 \mathrm{~min}$. The hexane was then removed. The embryos were washed once with X-gal (5-bromo-4-chloro-3-indolyl- $\beta$-galactopyranoside) staining buffer $\left[3.3 \mathrm{mM} \mathrm{K} \mathrm{K}_{3} \mathrm{Fe}(\mathrm{CN})_{6}\right.$, $3.3 \mathrm{mM} \mathrm{K}_{4} \mathrm{Fe}(\mathrm{CN})_{6}, 10 \mathrm{mM} \mathrm{NaCl}$ phosphate, $150 \mathrm{mM} \mathrm{NaCl}, 1$ $\mathrm{mM} \mathrm{MgCl}_{2}$ ] containing $0.4 \%$ Triton, and stained with $0.2 \%$ $\mathrm{X}$-gal in X-gal staining buffer at room temperature in the dark. The stained embryos were transferred onto a Boerner slide and photographed.

C-gal assay of adult flies This assay was basically performed as described by Simon and Lis (1987), except that cell debris in the fly extracts was removed by centrifugation before being used in the C-gal (chlorophenol Red- $\beta$-D-galactopyranoside) reaction.

\section{Chloramphenicol acetyltransferase activity assay of cell extracts}

Extracts of cells transfected with the Copia-CAT fusion gene were prepared as described in the ONPG assay section. Cell extracts $(30 \mu \mathrm{l})$ were used in the CAT activity assay described by Gorman et al. (1982). For quantitation, the radioactive spots were cut out and counted after adding scintillation fluid in a scintillation counter. One unit of CAT activity was defined as $100 \%$ conversion of substrate to product.

\section{Acknowledgments}

We thank Janis Werner for excellent assistance in Drosophila germ-line transformation experiments; J. Tso, J. Simon, H. Xiao, and R. Glaser for extensive discussions; and R. Glaser for help in photography. We also thank I. Dawid for the Copia-CAT plasmid. This work is supported by grants GM29179 and GM25232 from the National Institutes of Health, U.S. Public Health Service.

\section{References}

Amin, J., R. Mestril, R. Lawson, H. Klapper, and R. Voellmy. 1985. The heat shock consensus sequence is not sufficient for hsp70 gene expression in Drosophila melanogaster. Mol. Cell. Biol. 5: 197-203.

Benoist, C. and P. Chambon. 1980. In vivo sequence require- ments of the SV40 early promoter region. Nature 290: 304310.

Casadaban, M.J., J. Chou, and S.N. Cohen. 1980. In vitro gene fusions that join an enzymatically active $\beta$-galactosidase segment to amino-terminal fragments of exogenous proteins: Escherichia coli plasmid vectors for the detection and cloning of translational initiation signals. I. Bacteriol. 143: 971-980.

Di Nocera, P.P. and I. Dawid. 1983. Transient expression of genes introduced into cultured cells of Drosophila. Proc. Natl. Acad. Sci. 80: 7095-7098.

Glaser, R.L., M.F. Wolfner, and J.T. Lis. 1986. Spatial and temporal pattern of hsp26 expression during normal development. $E M B O$ I. 5: 747-754.

Goodbourn, S., H. Burstein, and T. Maniatis. 1986. The human $\beta$-interferon gene enhancer is under negative control. Cell 45: $601-610$.

Gorman, C.M., L.F. Moffat, and B.H. Howard. 1982. Recombinant genomes which express chloramphenicol acetyltransferase in mammalian cells. Mol. Cell. Biol. 2: 1044-1051.

Guo, L.-H. and R. Wu. 1983. Exonuclease III: Use for DNA sequence analysis and in specific deletion of nucleotides. Methods Enzymol. 100: 60-96.

Guarente, L. 1984. Yeast promoters: Positive and negative elements. Cell 36: 799-800.

Hultmark, D., R. Klemenz, and W.J. Gehring. 1986. Translational and transcriptional control elements in the untranslocated leader of the heat-shock gene hsp22. Cell 44: 429438.

Johnson, A.D. and I. Herskowitz. 1985. A repressor (MATa2 product) and its operator control expression of a set of cell type specific genes in yeast. Cell 42: 237-247.

Kadonaga, J.T. and R. Tjian. 1986. Affinity purification of sequence-specific DNA binding proteins. Proc. Natl. Acad. Sci. 83: 5889-5893.

Karin, M., A. Haslinger, H. Holtgreve, R.I. Richards, P. Krauter, H.M. Westphal, and M. Beato. 1984. Characterization of DNA sequences through which cadmium and glucocorticoid hormones induce human metallothionein-IIA gene. Nature 308: 513-519.

Lis, J.T., J.A. Simon, and C.A. Sutton. 1983. New heat shock puffs and $\beta$-galactosidase activity resulting from transformation of Drosophila with an hsp70-lacZ hybrid gene. Cell 35: 403-410.

Maniatis, T., E.F. Fritsch, and J. Sambrook. 1982. Molecular cloning: A laboratory manual. Cold Spring Harbor Laboratory, Cold Spring Harbor, New York.

Maniatis, T., S. Goodbourn, and J.A. Fischer. 1987. Regulation of inducible and tissue-specific gene expression. Science 236: $1237-1244$.

McKnight, S.L. and R. Tiian. 1986. Transcriptional selectivity of viral genes in mammalian cells. Cell 46: 795-805.

Nir, U., M.D. Walker, and W.J. Rutter. 1986. Regulation of rat insulin-1 gene expression: Evidence for negative regulation in nonpancreatic cells. Proc. Natl. Acad. Sci. 83: 31803184.

Schneider, I. and A.B. Blumenthal. 1978. Drosophila cell and tissue culture. In The genetics and biology of Drosophila. (ed. M. Ashburner and T.R.F. Wright), vol. 2a, pp. 266-315. Academic Press, New York.

Simon, J.A. and J.T. Lis. 1987. A germline transformation analysis reveals flexibilty in the organization of heat shock consensus elements. Nucleic Acids Res. 15: 2971-2988.

Struhl, K. 1987. Promoters, activator proteins, and the mechanism of transcriptional initiation in yeast. Cell 49: 295297. 
Sun, X.-H. 1987. "Differential regulation of the genes encoding glyceraldehyde-3-phosphate dehydrogenase in the development of Drosophila". Ph.D. thesis, Cornell University, Ithaca, New York.

Tso, J.Y., X.-H. Sun, and R. Wu. 1985. Structure of two unlinked Drosophila melanogaster glyceraldehyde-3-phosphate dehydrogenase genes. I. Biol. Chem. 260: 8220-8228.

Wieschaus, E. and C. Nüsslein-Volhard. 1986. Looking at embryos. In Drosophila: A practical approach. (ed. D.B. Roberts), pp. 199-227. IRL Press, Washington, DC. 


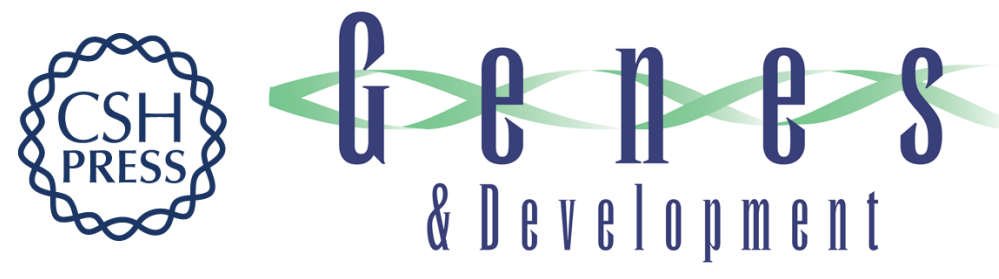

\section{The positive and negative transcriptional regulation of the Drosophila Gapdh-2 gene.}

$\mathrm{XH}$ Sun, $\mathrm{J} \mathrm{T}$ Lis and $\mathrm{R} \mathrm{Wu}$

Genes Dev. 1988, 2:

Access the most recent version at doi:10.1101/gad.2.6.743

References This article cites 20 articles, 8 of which can be accessed free at: http://genesdev.cshlp.org/content/2/6/743.full.html\#ref-list-1

License

Email Alerting

Service

Receive free email alerts when new articles cite this article - sign up in the box at the top right corner of the article or click here.

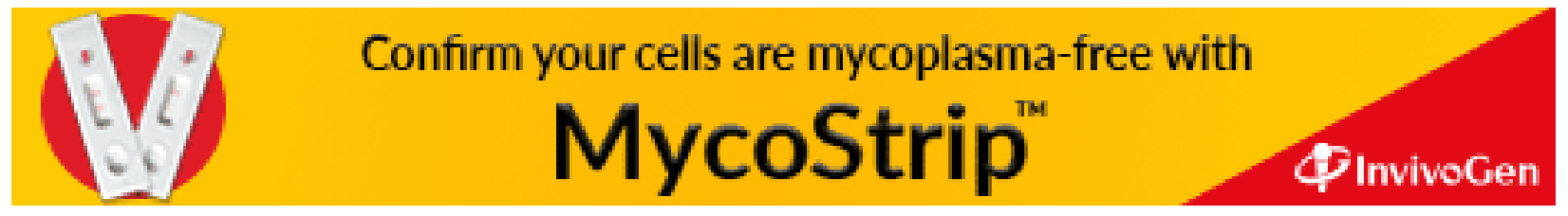

